\title{
8
}
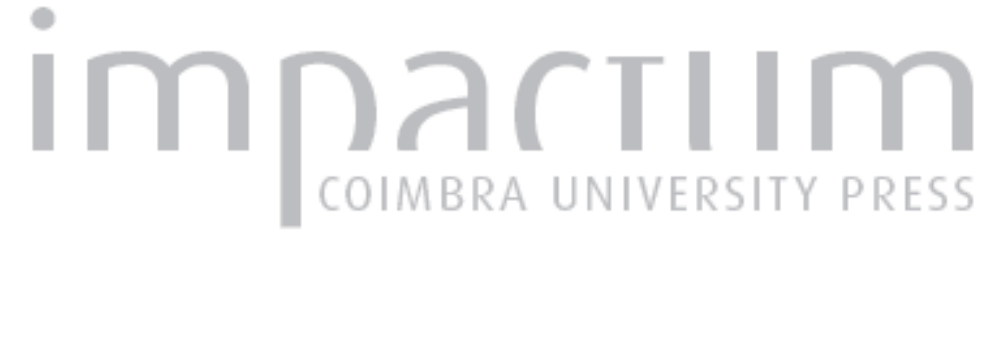

\section{Movimentos verticais excessivos de um navio em manobra: avaliação da probabilidade de ocorrência} \author{
Autor(es): $\quad$ Santos, João Alfredo; Fortes, Conceição Juana; Reis, Maria Teresa; \\ Publicado por: Associação Portuguesa de Riscos, Prevenção e Segurança \\ URL \\ persistente: \\ URI:http://hdl.handle.net/10316.2/35844 \\ DOI: \\ DOI:http://dx.doi.org/10.14195/1647-7723_20_11

\section{Accessed : $\quad$ 26-Apr-2023 13:09:11}

A navegação consulta e descarregamento dos títulos inseridos nas Bibliotecas Digitais UC Digitalis, UC Pombalina e UC Impactum, pressupõem a aceitação plena e sem reservas dos Termos e Condições de Uso destas Bibliotecas Digitais, disponíveis em https://digitalis.uc.pt/pt-pt/termos.

Conforme exposto nos referidos Termos e Condições de Uso, o descarregamento de títulos de acesso restrito requer uma licença válida de autorização devendo o utilizador aceder ao(s) documento(s) a partir de um endereço de IP da instituição detentora da supramencionada licença.

Ao utilizador é apenas permitido o descarregamento para uso pessoal, pelo que o emprego do(s) título(s) descarregado(s) para outro fim, designadamente comercial, carece de autorização do respetivo autor ou editor da obra.

Na medida em que todas as obras da UC Digitalis se encontram protegidas pelo Código do Direito de Autor e Direitos Conexos e demais legislação aplicável, toda a cópia, parcial ou total, deste documento, nos casos em que é legalmente admitida, deverá conter ou fazer-se acompanhar por este aviso. 


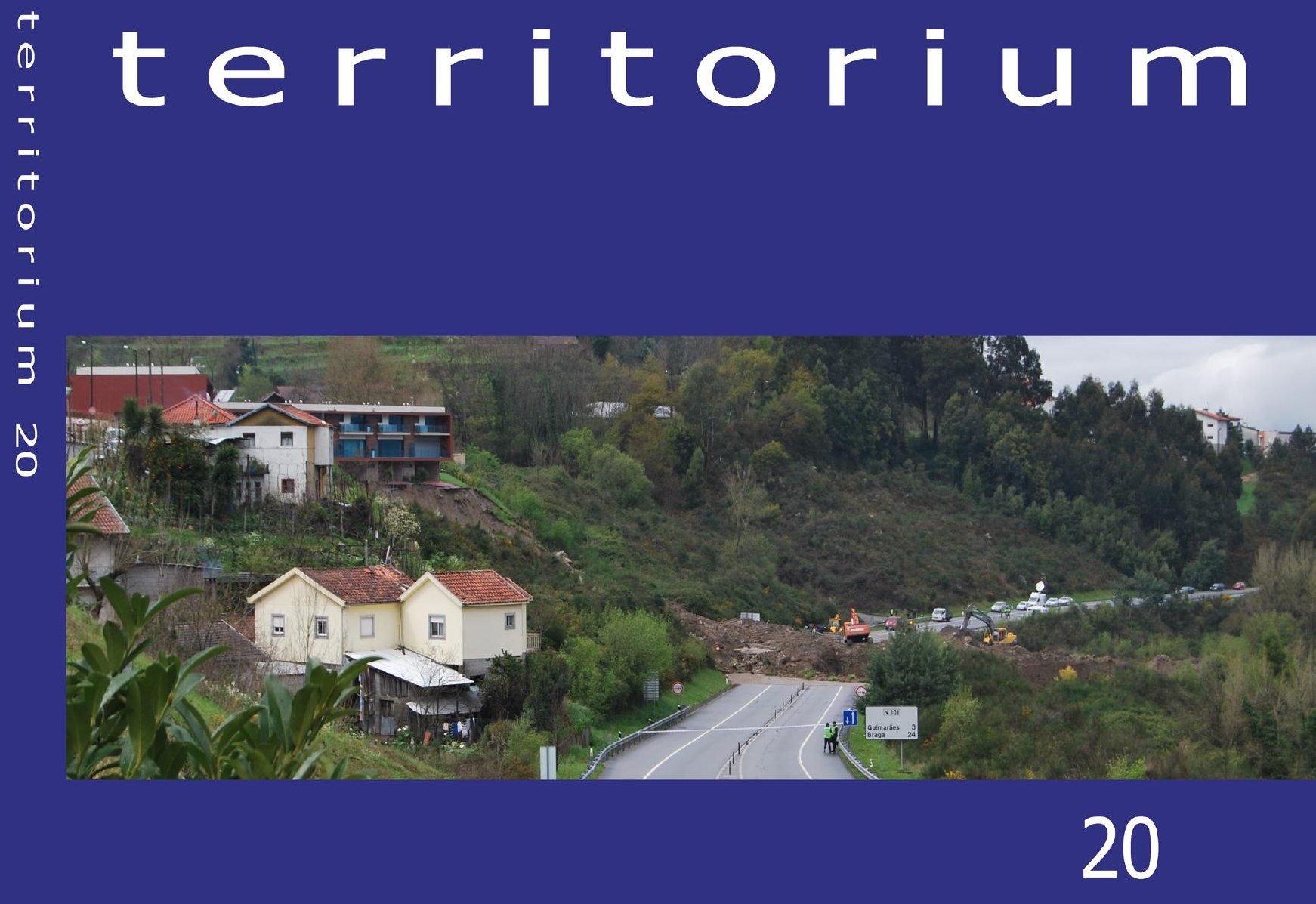

Riscos, População e Segurança 
Área Departamental de Engenharia Civil, Instituto Superior de Engenharia de Lisboa jasantos@dec.isel.pt

Conceição Juana Fortes

Núcleo de Portos e Estruturas Marítimas, Departamento de Hidráulica e Ambiente, LNEC jfortes@lnec.pt

Maria Teresa Reis

Núcleo de Portos e Estruturas Marítimas, Departamento de Hidráulica e Ambiente, LNEC treis@lnec.pt

Ricardo Pardillo Oliveira

Área Departamental de Engenharia Civil, Instituto Superior de Engenharia de Lisboa a23035@alunos.isel.pt

\section{RESUMO}

Descrevem-se os procedimentos para a avaliação da distribuição dos movimentos verticais de um navio em manobra numa bacia portuária e que incluem a definição da função resposta do navio a ondas monocromáticas nele incidentes, bem como a determinação das características da agitação marítima ao longo do trajeto do navio. Ilustra-se a influência da velocidade de avanço do navio naquela distribuição avaliando-se a probabilidade de ocorrência de movimentos verticais superiores a um limiar pré-definido na manobra de um navio no porto da Praia da Vitória, Açores.

Palavras-chave: Navegação, função resposta, distribuição de Rayleigh, Porto da Praia da Vitória.

\section{RESUMEN}

Movimientos verticales excesivos de un buque en maniobra. Evaluación de la probabilidad de ocurrencia - Se describen los procedimientos para la evaluación de la distribución de movimientos verticales de las maniobras de un buque en un puerto y que incluyen la definición de la función de respuesta del buque a ondas incidentes monocromáticas y la determinación de las características del oleaje a lo largo del trayecto del buque. Se muestra la influencia de la velocidad de avance del buque en aquella distribución mediante la evaluación de la probabilidad de movimientos verticales superiores a un umbral predefinido en las maniobras de un buque en el puerto de Praia da Vitória, Açores.

Palabras clave: Navegación, función de respuesta,distribución de Rayleigh, Puerto de Praia da Vitória.

\section{RÉSUMÉ}

Mouvements verticaux excessifs d'un navire en manœuvre. Evaluation de la probabilité d'occurrence - On décrit les procédures d'évaluation de la distribution des mouvements verticaux d'un navire en manœuvre dans un bassin portuaire et qui incluent la définition de la fonction de réponse du navire à houles incidentes monochromatiques, ainsi que la détermination des caractéristiques des houles le long du trajet du navire. On illustre l'influence de la vitesse d'avancement du navire sur cette distribution en évaluant la probabilité de mouvements verticaux qui dépassent un seuil prédéfini dans la manœuvre d'un navire dans le port de Praia da Vitória, Açores.

Mots-clé: Navigation, fonction de réponse, distribution de Rayleigh, Port de Praia da Vitória.

\section{ABSTRACT}

Excessive vertical movements of a manoeuvring ship. Evaluation of occurrence probability - The procedures for the evaluation of vertical movements of a manoeuvring ship are described. Such procedures include the definition of the ship response to monochromatic waves as well as the evaluation of the sea wave characteristics along the ship trajectory. The influence of the ship speed on that distribution is illustrated with the evaluation of the occurrence probability for vertical movements above a pre-set threshold for a ship manoeuvring in the Praia da Vitória port, Azores.

Keywords: Navigation, response function, Rayleigh distribution, Port of Praia da Vitória.

* O texto deste artigo corresponde à comunicação apresentada ao VII Encontro Nacional de Riscos e I Forum ISCIA, tendo sido submetido para revisão em 07-11-2012, e aceite para publicação em 12-11-2012.

Este artigo é parte integrante da Revista Territorium, n. ${ }^{\circ} 20,2013,{ }^{\circ}$ RIscos, ISBN: 0872- 8941. 


\section{Introdução}

O desenvolvimento de modelos numéricos como o WAVEWATCH III, H.R. ToLmAN (1999), capazes de prever as características da agitação marítima à escala oceânica a partir de valores medidos / extrapolados da velocidade e rumo do vento sobre essas regiões, permite colmatar a falta de dados de agitação medidos ao largo criando séries longas de características da agitação marítima em qualquer ponto da zona marítima adjacente a uma bacia portuária ou mesmo no interior dessa bacia. Tal abundância de dados facilita a avaliação de riscos associados aos efeitos da agitação marítima nas diversas vertentes das atividades portuárias.

Por essa razão começou a ser desenvolvido no LNEC um sistema integrado de modelação costeira e portuária, GUIOMAR (A.C.Zózimo e C.J.E.M.Fortes 2007; D.R.C.B. NEvES et al., 2009) com base no software comercial $\operatorname{ArcGis}^{T M} e$ que permite a utilização de vários modelos numéricos de propagação de ondas num ambiente SIG. Este sistema foi criado para apoiar a tomada de decisão na gestão de processos característicos de zonas costeiras e portuárias.

Os modelos numéricos de propagação de ondas transformam as características da agitação marítima prevista ao largo nas características da agitação marítima em qualquer ponto da bacia portuária. Contudo, a aplicação destes modelos numéricos é complexa e requer tempo, quer para a preparação dos dados de entrada, quer para a análise dos resultados obtidos, devido às grandes quantidades de informação envolvidas. Daí o interesse na utilização de Sistemas de Informação Geográfica (SIG) pois permitem uma análise espacial e temporal de informação correspondente a fenómenos naturais complexos através da amostra de tendências e padrões que são essenciais para qualquer processo rápido de tomada de decisão. Com efeito, os sistemas SIG têm a capacidade de facilmente produzir mapas de risco de acordo com procedimentos automáticos baseados em dados e resultados de modelos numéricos, facilitando o processo de tomada de decisão na gestão costeira e portuária.

Neste momento, já está consolidado no sistema GUIOMAR a avaliação do risco associado ao galgamento de quebra-mares de taludes e proteções marginais. Para o cálculo da probabilidade de ocorrência de caudais de galgamento excessivos utilizaram-se modelos de comportamento das estruturas face às ondas que foram desde as formulações empíricas usuais, E. SiLva et al. (2011), até ferramentas baseadas na utilização de redes neuronais, D.R. NEves et al. (2012).

O objectivo desta comunicação é apresentar uma metodologia para avaliar a probabilidade de ocorrência de movimentos verticais excessivos de um navio em manobra no acesso a uma bacia portuária, contribuindo assim para a avaliação deste risco. Depois dos primeiros trabalhos (S. Rodrigues et al., 2011A) em que se consideraram apenas ondas monocromáticas incidentes no navio, pois isso tornava mais simples a determinação da frequência de encontro do navio com as ondas, em S. RodRIgues et al. (2011B) utilizaram-se os resultados da resposta de sistemas lineares para determinar o espectro da resposta - definida como a altura do movimento vertical de um ponto selecionado do navio em manobra - uma vez conhecido o espectro do estado de agitação incidente no navio, a função de resposta em frequência do navio e a velocidade de avanço deste. Com aquela abordagem, e assumindo que o espectro do estado de agitação incidente no navio era de banda estreita, foi possível determinar uma altura significativa do movimento vertical do navio, definindo-se então como acontecimento perigoso a ultrapassagem de um limiar para aquela altura significativa. Pretende-se agora implementar outra metodologia baseada no valor esperado do número de vezes que é ultrapassado um limiar para a altura do movimento induzido por cada onda de um estado de agitação incidente no navio. A adoção de tal critério terá a vantagem de tornar mais fácil a associação de um custo ao mesmo pois é expetável que seja mais fácil atribuir um custo à ultrapassagem de um limiar para a altura dos movimentos do que para a ultrapassagem de um limiar para a altura significativa dos movimentos.

Depois deste capítulo de introdução, descrevem-se as ideias básicas subjacentes à metodologia de cálculo do risco, apresentando-se em seguida os procedimentos para avaliação da probabilidade de ocorrência de movimentos verticais excessivos do navio em manobra. Finalmente, descreve-se a aplicação desses procedimentos ao caso de estudo: a entrada de um navio no porto da Praia da Vitória. Determinam-se os valores da probabilidade de ocorrência obtidos a partir de dois anos de previsões da agitação marítima utilizando um limiar de $0.5 \mathrm{~m}$ para as alturas do mesmo movimento vertical de um ponto do navio e avalia-se a influência nos resultados da velocidade de avanço do navio. 0 artigo termina com a apresentação das conclusões do trabalho realizado.

\section{Metodologia de avaliação do risco}

Considere-se um navio em manobra sujeito à ação da agitação marítima, caraterizada por uma altura significativa $\left(\mathrm{H}_{\mathrm{s}}\right)$, um período de pico $\left(\mathrm{T}_{\mathrm{p}}\right)$ e uma direção média do período de pico (DIR). Em consequência dessa agitação marítima ocorrem movimentos verticais do navio caracterizados por $h$, a altura do movimento vertical de um ponto seleccionado do navio. Consoante o valor de $h$ assim variarão os prejuízos provocados pelos movimentos verticais do navio. 
Se as grandezas que condicionam a altura do movimento vertical do navio $(h)$ têm caráter aleatório, isto é, se $\mathrm{H}_{\mathrm{s}}, \mathrm{T}_{\mathrm{p}}$ ou DIR para cada estado de agitação incidente no navio podem ser consideradas variáveis aleatórias, então também $h$ pode ser considerada uma variável aleatória e é possível definir a função densidade de probabilidade para $h$, por exemplo $f(h)$. A mesma função servirá também para o cálculo do risco, $R$, ou seja, do valor esperado do prejuízo $c(h)$ associado à ocorrência de movimentos verticais do navio.

$$
R=\int_{0}^{+\infty} f(h) c(h) d h
$$

Como é natural, assumiu-se que é possível qualquer valor positivo para a variável $h$ ou para o prejuízo associado à mesma, sendo, por isso, a variável $c$ uma variável aleatória contínua.

$\mathrm{Na}$ falta de melhor informação sobre os prejuízos associados a todos os valores de $h$, poderia atribuir-se um valor ao prejuízo por gama de $h$, isto é:

$$
\begin{gathered}
h \leq h_{0} \Rightarrow c=0, \\
h_{0}<h \leq h_{1} \Rightarrow c=c_{1}, h_{1}<h \leq h_{2} \Rightarrow c=c_{2}, \\
\ldots, h_{n}<h \Rightarrow c=c_{n+1}
\end{gathered}
$$

vindo então o valor esperado da variável aleatória discreta

$$
R=P_{1} c_{1}+P_{2} c_{2}+\ldots+P_{n+1} c_{n+1}
$$

em que

$$
\begin{aligned}
& P_{1}=P\left(h_{0}<h \leq h_{1}\right)=\int_{h_{0}}^{h_{1}} f(h) d h \\
& P_{2}=P\left(h_{1}<h \leq h_{2}\right)=\int_{h_{1}}^{h_{2}} f(h) d h \\
& \vdots \\
& P_{n+1}=P\left(h_{n}<h\right)=\int_{h_{n}}^{+\infty} f(h) d h
\end{aligned}
$$

Uma abordagem ainda mais simples consiste em considerar apenas como acontecimento prejudicial a ocorrência de um valor de $h$ acima de um limiar préestabelecido $h_{0}$, assumindo-se que o prejuízo associado a esse acontecimento, $c_{1}$, se mantém constante qualquer que seja o valor de $h$ acima do mesmo limiar $h_{0}$. Embora tal abordagem se possa classificar de muito grosseira, ela tem a vantagem de tornar o cálculo do risco no produto da probabilidade de ocorrência do acontecimento considerado perigoso (a variável observada ultrapassou o limiar pré estabelecido), $P_{1}$, pelo prejuízo associado a essa ocorrência, $c_{1}$.

$$
R=P_{1} c_{1}
$$

Esta é a abordagem mais comum para a avaliação do risco e a que foi implementada no sistema integrado de modelação costeira e portuária GUIOMAR (D.R.C.B. Neves et al., 2009). Trata-se de um sistema que tem vindo a ser desenvolvido no LNEC para apoiar a tomada de decisão na gestão de processos característicos de zonas costeiras e portuárias.
Do exposto acima, fica clara que a determinação da probabilidade de ocorrência depende da chamada função de resposta do sistema relacionando as características da agitação marítima incidente no navio e a variável determinante da ocorrência de acontecimento perigoso (neste caso, a altura do movimento vertical de um ponto selecionado do navio).

Utilizando a função resposta em frequência, é possível determinar o espectro da resposta do sistema, a partir do qual se pode estimar a distribuição das alturas dos movimentos verticais do navio associada a um estado de agitação nele incidente. Pode então determinar-se a altura significativa dos movimentos verticais do ponto selecionado do navio ou mesmo o valor esperado do número de vezes que um dado limiar para a altura daquele movimento é excedido num dado estado de agitação.

Tomando os valores daquelas grandezas obtidos para uma sequência de estados de agitação incidentes no navio como uma amostra representativa de todos os valores que podem ser observados em cada posição da manobra do navio e utilizando uma abordagem frequencista, calcula-se a probabilidade da altura significativa, ou da altura, do movimento vertical do navio ultrapassar um limiar pré-fixado, isto é, a probabilidade de ocorrência necessária ao cálculo do risco associado a este fenómeno.

\section{Cálculo dos movimentos do navio}

As equações do movimento do navio estabelecem o equilíbrio dinâmico entre as forças de inércia associadas à massa do navio e as forças externas que actuam no navio, resultado das interacções entre o casco e o fluido.

O navio é considerado um corpo rígido que oscila em seis graus de liberdade. Os movimentos oscilatórios consistem em três translações segundo cada um dos eixos de coordenadas (oscilação longitudinal - "surge", abatimento - "sway", arfagem - "heave”), e três rotações em torno dos mesmos eixos (rolo - "roll”, galear - “ pitch”, guinada - "yaw”), fig. 1.

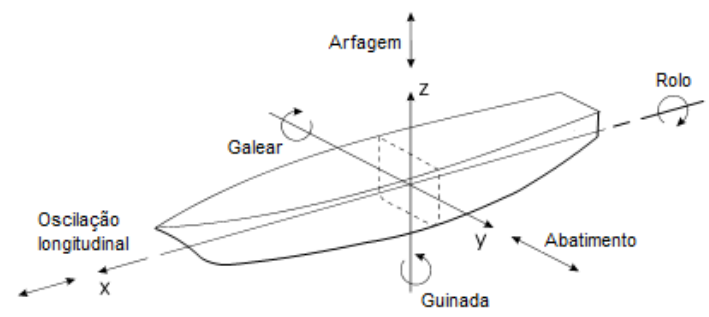

Fig. 1 - Movimentos do navio segundo cada um dos seis graus de liberdade.

S. Rodrigues et al., 2011A.

Os modelos numéricos para o cálculo dos potenciais dos problemas de difracção e de radiação foram desenvolvidos inicialmente para a indústria de exploração de petróleo ao largo da costa. Um desses 
modelos é o WAMIT, (J.N. Newman e P.D. Sclavounos, 1988), desenvolvido no Massachusets Institute of Technology.

Este modelo vai ser usado para determinar a resposta do navio, em termos da altura dos movimentos segundo cada um dos seis graus de liberdade do navio, para uma gama de períodos de onda, profundidades e ângulos entre o eixo longitudinal do navio e o vector número de onda expectável na zona em estudo. Trata-se de um modelo numérico em que se assume a linearidade da interacção entre o corpo flutuante e as ondas nele incidentes. Esta linearidade permite a decomposição daquela interacção em dois problemas mais simples: os chamados problemas de difracção e de radiação, fig. 2 .

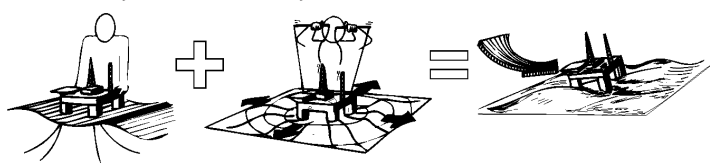

Fig. 2 - Decomposição da interacção de um corpo flutuante com as ondas nos problemas de difracção e de radiação. Fonte: Adaptado de O.M. Faltinsen (1990).

No problema de difracção determinam-se as forças exercidas pelas ondas incidentes no navio imobilizado na sua posição média, enquanto no problema de radiação se determinam as forças necessárias para deslocar o navio em águas de outra forma paradas. É também devido à linearidade desta interacção que é possível definir as funções potencial do campo de velocidades dos escoamentos associados a estes problemas:

$$
\phi=\phi^{D}+\phi^{R}
$$

Nesta equação $\phi$ designa o potencial para a interacção do corpo flutuante com as ondas, $\phi^{D}$ é o potencial do escoamento associado ao problema de difracção e $\phi^{R}$ o potencial do escoamento do problema de radiação. Problemas mais simples podem ser definidos estudando a interacção com ondas monocromáticas. Nesse caso o potencial de radiação pode escrever-se como o resultado da sobreposição dos potenciais associados à oscilação independente do navio segundo cada um dos seis graus de liberdade apresentados na fig. 1, vindo então $\phi$

$$
\phi=\left[\varphi_{0}+\varphi_{7}+\sum_{j=1}^{6}-i \omega \varphi_{j} \varepsilon_{j}\right] e^{-i \omega t}
$$

em que $\omega$ é a frequência das ondas monocromáticas, $\varepsilon_{j}$ é a amplitude complexa da oscilação segundo a coordenada generalizada $j$ e $\varphi_{0}$ a $\varphi_{7}$ designam a variação espacial dos potenciais associados ao problema de difracção $\left(\varphi_{0}\right.$ e $\left.\varphi_{7}\right)$ e ao problema de radiação $\left(\varphi_{1}\right.$ a $\left.\varphi_{6}\right)$. Porque o escoamento em torno do casco é claramente tridimensional, isso implica que no problema de radiação o movimento segundo uma das coordenadas generalizadas produzirá certamente forças segundo outras coordenadas generalizadas (i.e. existirá interferência mútua entre os vários modos de oscilação).
Decompondo as forças do problema de radiação nas componentes em fase com a aceleração e com a velocidade do navio, isto é tomando as partes real e imaginária de

$$
F_{k j}^{R} \rho \int_{S_{B}} \varphi_{j} n_{k} d S
$$

obtêm-se os chamados coeficientes de massa adicionada e de amortecimento, respectivamente, $a_{k j}$ e $b_{k j}$ :

$$
\begin{array}{r}
a_{k j}=-\rho \operatorname{Re}\left[\int_{S_{B}} \varphi_{j} n_{k} d S\right] \\
b_{k j}=-\rho \omega \operatorname{Im}\left[\int_{S_{B}} \varphi_{j} n_{k} d S\right]
\end{array}
$$

$n_{k}$ é a componente segundo a coordenada generalizada $k$ do vector normal à superfície molhada do casco, $S_{B}$. Assim, $a_{k j}$ é $1 / \omega^{2}$ da componente da força segundo a coordenada $k$ em fase com a aceleração do corpo quando ocorre uma oscilação forçada segundo $j$ e $b_{k j}$ é $1 / \omega$ da componente da força em fase com a velocidade do corpo.

\section{Função resposta em frequência}

A caracterização do movimento vertical de um ponto seleccionado no navio sujeito a uma agitação irregular qualquer pode realizar-se utilizando os resultados no domínio da frequência. Tal deve-se à inexistência de componentes de segunda ordem significativas nas forças actuantes no navio quando este se desloca na entrada ou no interior do porto. Assim é possível determinar o espectro da resposta do movimento desse ponto, $S_{R}(\omega)$, a partir do espectro da agitação incidente no navio, $S(\omega)$, e da função de resposta em frequência (em termos da amplitude da oscilação desse ponto no navio) nos pontos que definem as trajectórias do navio.

$$
S_{R}(\omega)=|H(\omega)|^{2} S(\omega)
$$

A função de resposta em frequência pode ser obtida através da solução das equações para o movimento estacionário do navio livre:

$\sum_{j=1}^{6}\left[\left(M_{k j}+a_{k j}\right) \ddot{\xi}_{j}+b_{k j} \dot{\xi}_{j}+C_{k j} \xi_{j}\right]=F_{k}^{E} \quad k=1, \ldots, 6$

em que $M_{k j}$ e $C_{k j}$ são, respectivamente, as matrizes de massas e de restituição hidrostática do navio, $a_{k j}$ e $b_{k j}$ são os coeficientes de massa adicionada e de amortecimento, e $F_{k}^{E}$ designa a força de excitação devida às ondas (associadas ao problema de difracção) segundo a coordenada generalizada $k$ para ondas monocromáticas de amplitude unitária e frequênciam $\omega$ cujo vector número de onda faz um ângulo $\beta$ com o eixo longitudinal do navio. $\xi_{\mathrm{j}}$ representa a amplitude da oscilação segundo a coordenada generalizada $j$ do ponto seleccionado no navio, enquanto $\dot{\xi}_{j}$ e $\ddot{\xi}_{j}$ designam, respectivamente, a velocidade e a aceleração da mesma oscilação. 
As soluções das equações diferenciais lineares de segunda ordem, equação (12), são movimentos do tipo harmónico:

$$
\xi_{j}(t)=\operatorname{Re}\left\{\xi_{j}^{A}(\omega) e^{i \omega t}\right\}=\left|\xi_{j}^{A}\right| \cos \left(\omega t+\theta_{j}\right)
$$

onde $\xi_{j}^{A}$ é a amplitude complexa do movimento oscilatório e $\theta_{j}$ é a fase do movimento em relação à passagem da onda na posição do centro de gravidade do navio (i.e. o atraso da resposta no tempo). De acordo com a equação anterior, a função de transferência de resposta do sistema é dada pela amplitude do movimento do navio, sendo

$$
H_{j}(\omega)=\left|\xi_{j}^{A}(\omega)\right|
$$

\section{Resposta do navio à agitação incidente}

Conhecidas as características da agitação marítima nas várias posições ocupadas pelo navio, é possível avaliar o espectro de resposta do navio, isto é, o espectro do movimento vertical do navio ao longo da sua trajectória de entrada num porto.

Neste estudo, assume-se que a agitação marítima incidente no navio pode ser caracterizada por um espectro JONSWAP (K. HASSELMANn et al., 1973)

$S(\omega)=\alpha g^{2}(2 \pi)^{-4} \omega^{-5} \exp \left[-\frac{5}{4}\left(\frac{\omega}{\omega_{p}}\right)^{-4}\right] \gamma^{\exp \left[-\left(\omega-\omega_{p}\right)^{2} / 2 \sigma^{2} \omega_{p}^{2}\right]}$

onde $\omega_{p}$ designa a frequência de pico, $\sigma$ o coeficiente que traduz a assimetria do espectro e $\gamma$ o parâmetro de realce do pico. Valores típicos para alguns daqueles parâmetros são $a=810 \times 10^{-3}, \quad y=3.3$ e $\sigma=\sigma_{a}=0.07$, para $\omega \leq \omega_{P}$, e $\sigma=\sigma_{b}=0.09$, para $\omega>\omega_{P}$. Quanto à frequência de pico, ela pode determinar-se por

$$
\omega_{p}=(2 \pi)^{-1}(4 \beta / 5)^{\frac{1}{4}} g U_{19.5}^{-1}
$$

com $\beta=0.74$ e $U_{19.5}$ a velocidade do vento a $19.5 \mathrm{~m}$ de altura.

Uma vez que o espectro da agitação incidente deve ser determinado a partir da altura significativa, $H_{s}$, e do período de pico, $T_{p}$, que são os parâmetros utilizados para caracterizar os estados de agitação nos modelos numéricos para propagação de ondas, utilizou-se a reparametrização do espectro JONSWAP proposta em Y. Goda (1985):

$S(\omega)=\beta H_{S}^{2} T_{p}^{-4}\left(\frac{\omega}{2 \pi}\right)^{-5} \exp \left[-\frac{5}{4}\left(\frac{T_{p} \omega}{2 \pi}\right)^{-4}\right] \gamma^{\exp \left[-\left(2 \pi T_{p} \omega-1\right)^{2} / 2 \sigma^{2}\right]}$

Importa referir que nesta análise não se leva em conta a distribuição direcional da energia associada ao estado de agitação. Isto é, assume-se que, em cada ponto onde se estimaram as características da agitação incidente, as ondas têm apenas o rumo estimado pelo modelo numérico.

Sendo o espectro da agitação incidente no navio de banda estreita, não é difícil assumir que o espectro da resposta do navio também o será. Nesse caso, pode afirmar-se que as alturas dos movimentos verticais do ponto seleccionado do navio seguem uma distribuição de Rayleigh, tal como acontece com as alturas das ondas individuais na série temporal do estado de agitação incidente no navio. Assim, é possível determinar a altura significativa dos movimentos verticais do navio, $\mathrm{H}_{\text {Snavio }}$, a partir do espectro da resposta do mesmo

$$
H_{\text {Snavio }} \approx 4 \sqrt{m_{0}}=4 \sqrt{\int_{0}^{\infty} S_{R}(\omega) d \omega}
$$

Determinando o período médio de zero ascendente dos movimentos verticais do navio a partir dos momentos de ordem zero e dois do espectro de resposta

$$
T_{\text {Znavio }}=\sqrt{\frac{m_{0}}{m_{2}}}=\sqrt{\frac{\int_{0}^{\infty} S_{R}(\omega) d \omega}{\int_{0}^{\infty} \omega^{2} S_{R}(\omega) d \omega}}
$$

pode calcular-se o número de "ondas" naqueles movimentos verticais, $N_{\text {navio }}$, e, a partir deste número, o valor esperado de movimentos verticais com altura acima de um dado limiar $H, N_{H}$, correspondente a um estado de agitação de duração conhecida, $T_{\text {agitação }}$

$$
N_{H}=\frac{T_{\text {agitação }}}{T_{\text {Znavio }}} \exp \left[\frac{2 H^{2}}{H_{\text {Snavio }}^{2}}\right]
$$

\section{Frequência de encontro}

Quando o navio está em movimento, a frequência com que ele encontra as ondas, e que é relevante para a resposta do navio às ondas nele incidentes, irá depender da velocidade do navio, $U$, da velocidade de propagação das ondas, $c$, e da direcção de propagação das ondas em relação ao navio, $\beta$, diferindo da frequência de onda real devido ao efeito Doppler. A fig. 3 ilustra estas grandezas.

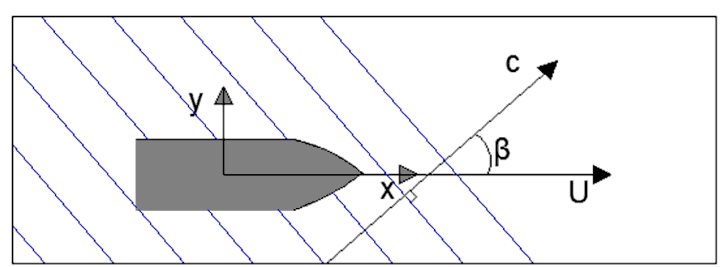

Fig. 3 - Movimento do navio em relação às ondas. Fonte: S. RodRIGues et al., 2011A.

A velocidade relativa de encontro, $v_{r}$, determina-se subtraindo à velocidade de propagação das ondas, $c$, a componente da velocidade de avanço do navio segundo o vector velocidade de propagação, $U \cos \beta$. Resulta então

$$
v_{r}=c-U \cos \beta
$$

O período de encontro é calculado pela expressão

$$
T_{e}=\frac{L}{c-U \cos \beta}
$$

e a frequência de encontro $\omega_{e}=2 \pi / T_{e}$ é dada por

$$
\omega_{e}=\omega-\frac{U}{k} \cos \beta
$$


em que $k=2 \pi / L$ é o número de onda, uma quantidade que depende da frequência angular da onda e da profundidade da zona sobre a qual a onda se propaga.

Face ao exposto, as ordenadas do espectro de resposta calculam-se por

$$
S_{R}(\omega)=\left|H\left(\omega_{e}\right)\right|^{2} S(\omega)
$$

\section{Caso de estudo}

Neste capítulo apresenta-se a avaliação da probabilidade de ocorrência de movimentos verticais excessivos na viagem de entrada do "N/M Fernão Gomes" no porto da Praia da Vitória. Este porto localiza-se na costa Este da ilha Terceira, uma das nove ilhas do arquipélago dos Açores (Portugal), fig. 4. Trata-se de um pequeno porto protegido por dois molhes que definem uma baía aproximadamente rectangular com cerca de $1 \mathrm{~km} \times 2 \mathrm{~km}$.

Foram consideradas duas trajetórias de entrada do navio, ambas começando frente à entrada do porto no ponto P1 da fig. 5: uma das trajetórias dirige-se para sul, terminando frente ao cais 12 do porto da Praia da Vitória (Trajeto Sul) e a outra termina frente ao terminal de combustíveis da Base Aérea ${ }^{\circ}$. 4 (Trajeto Norte).
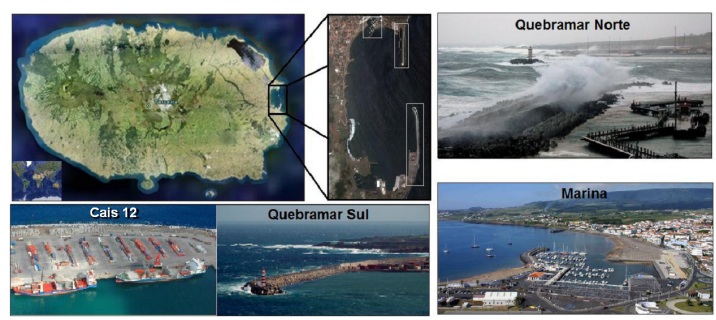

Fig. 4 - Porto da Praia da Vitória.

Em vez de se determinar a probabilidade de ocorrência em todos os pontos ao longo daqueles trajetos, determinou-se apenas nos centroides dos trechos em que se dividiu cada uma das duas regiões varridas pelo navio naquelas viagens de entrada. Na fig. 5 apresentamse aqueles pontos enquanto no QUADRo I se listam não só as profundidades em cada um daqueles pontos, como também o rumo do navio nos mesmos.

QuAdRo I - Profundidades e rumos do navio nos centroides dos troços em que foram divididos os percursos de entrada estudados.

\begin{tabular}{|r|r|r|r|r|}
\hline & \multicolumn{4}{|c|}{ Trajeto Sul } \\
\cline { 2 - 5 } & P1 & P2 & P3 & P4 \\
\hline Prof. (m) & 37.90 & 19.72 & 17.93 & 8.89 \\
\hline Rumo navio ( $\left.{ }^{\circ}\right)$ & 270 & 225 & 225 & 180 \\
\hline \multicolumn{5}{|c|}{ Trajeto Norte } \\
\hline & P1 & P2B & P5 & P6 \\
\hline Prof. (m) & 37.90 & 19.72 & 12.51 & 12.02 \\
\hline Rumo navio ( $\left.{ }^{\circ}\right)$ & 270 & 270 & 315 & 0 \\
\hline
\end{tabular}

Como já mencionado anteriormente, as características da agitação marítima são determinantes para a resposta do navio. Assim, utilizam-se os módulos do sistema integrado GUIOMAR para propagação das estimativas da agitação marítima para a bacia portuária da Praia da Vitória, i.e., ao longo das duas trajetórias do navio. Depois, calculam-se os correspondentes valores da altura do movimento vertical do navio e da altura significativa do mesmo movimento vertical, para uma dada velocidade de avanço. É efetuada uma avaliação da influência da velocidade de avanço do navio na probabilidade de ultrapassagem de limiares para a altura do movimento vertical do navio e para a altura significativa do mesmo movimento vertical. Finalmente calcula-se o risco associado a movimentos verticais excessivos.

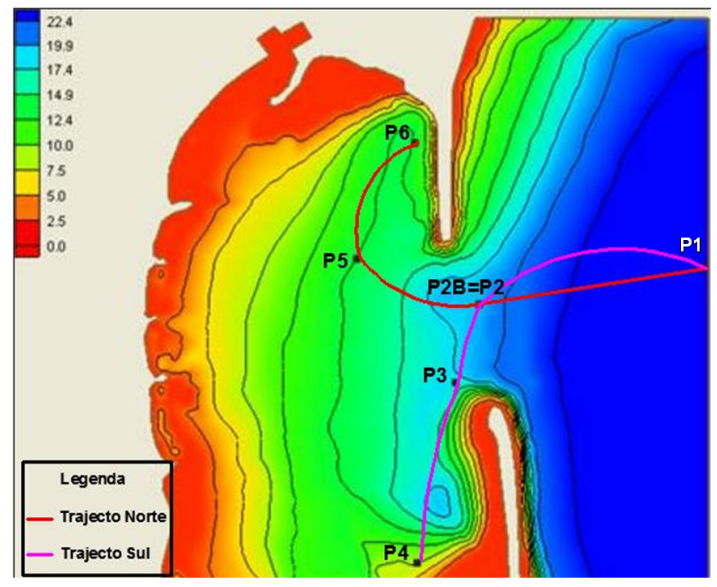

Fig. 5 - Trajetórias e centroides dos trechos em que se dividiu a zona varrida pelo "N/M Fernão Gomes" na manobra de entrada no porto da Praia da Vitória. Fonte: S. RodRIGUes et al., 2011B.

\section{Agitação marítima na entrada e no interior do porto}

$\mathrm{Na}$ caracterização da agitação marítima ao largo do porto em estudo recorreu-se a modelos de previsão de escala regional. Assim partindo de um campo de ventos (também fornecido por modelos numéricos, R. TомÉ et al. (2005)), o modelo WAVEWATCH III, H.L. TOLMAN (1999), prevê as características da agitação marítima na região do arquipélago, A. SimõEs et al. (2009). Para efetuar a caracterização da agitação marítima na bacia portuária da Praia da Vitória e, mais concretamente, ao longo do Trajeto Sul e do Trajeto Norte, utilizaram-se dois modelos numéricos acoplados para propagação de ondas: o modelo SWAN, N. Bools et al. (1999), e o modelo DREAMS, C.J.E.M. FORTES (2002).

Assim, obtiveram-se primeiramente os valores da agitação marítima no ponto P1 (exterior ao porto) com o modelo SWAN, que foram transferidos para o interior do porto com o modelo DREAMS, correspondentes aos valores nos restantes pontos dos dois trajetos, P2 a P6, fig. 5. A razão para a utilização destes dois modelos numéricos deve-se à inexistência de um único modelo 
capaz de simular, de forma computacionalmente eficaz, a propagação da agitação marítima nesta vasta região tendo em conta todos os fenómenos relevantes para aquela propagação. A metodologia encontra-se descrita em pormenor em D.R. Neves et al . (2012).

Neste trabalho, o conjunto de dados utilizados perfaz um total de 14573 valores horários correspondentes a 2 anos de previsões, desde o dia 1 de janeiro de 2009 até 31 de dezembro de 2010. Entre os dias 6 de julho de 2010 e 13 de outubro de 2010 houve uma interrupção nas previsões da agitação marítima com o modelo WAVEWATCH III. No estudo da propagação da agitação marítima com os modelos SWAM e DREAMS considerou-se o nível de maré constante e igual a $+1.4 \mathrm{~m}$ (Z.H.), isto é, o nível de maré acrescido de uma sobrelevação meteorológica de $0.4 \mathrm{~m}$. $\mathrm{Na}$ fig. 6 e na fig. 7 apresentam-se as séries temporais da altura significativa e do rumo da agitação para cada ponto das duas trajetórias do navio.
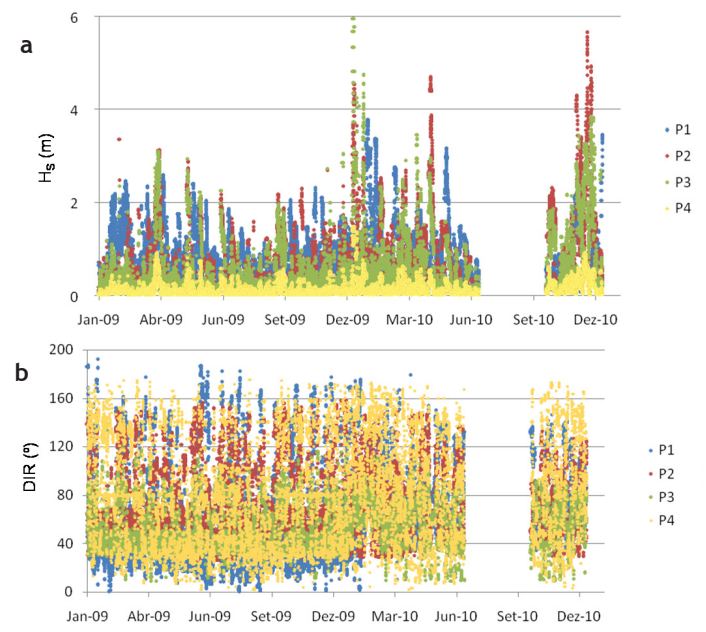

Fig. 6 - Série temporal dos valores da altura significativa $\left(\mathrm{H}_{\mathrm{s}}\right)$ (a) e direcção média ( DIR) (b) para os pontos do Trajecto Sul.

Na fig. 6 e na fig. 7 verifica-se que os pontos P4, P5 e P6 apresentam valores de altura significativa $\left(H_{S}\right)$ inferiores aos restantes pontos. Este é um resultado expectável pois são os pontos que se encontram mais protegidos da agitação incidente no porto. Por outro lado, os pontos P2 e P3, como se localizam na entrada do porto, ficam mais expostos às ondas incidentes. $\mathrm{O}$ ponto $\mathrm{P} 1$, estando localizado no exterior do porto, é aquele que apresenta valores mais elevados de $H_{S}$.

O QuAdRo II apresenta os valores dos parâmetros estatísticos (máximo, mínimo, média, desvio padrão e gama mais frequente) das variáveis caracterizadoras da agitação marítima, para todos os pontos (P1 a P6) dos dois trajectos de entrada do navio no porto.

Da análise deste quadro, pode constatar-se a diminuição da altura significativa da agitação marítima do ponto P1, no exterior do porto, para o ponto $\mathrm{P} 6$. $\mathrm{O}$ valor médio de $H_{S}$ atinge o máximo no ponto $\mathrm{P} 1$ com $0.85 \mathrm{~m}$ e o valor mínimo no ponto $\mathrm{P} 6$ com $0.06 \mathrm{~m}$.
Relativamente à direcção das ondas, o QUADRo II mostra que os pontos localizados perto da entrada do porto, P2 e P3, apresentam pouca variação na direcção da onda face à direcção da onda incidente no porto. Por outro lado, os pontos mais protegidos, P4 e P6, apresentam uma maior dispersão nos valores das direcções das ondas incidentes, logo desvios padrão mais elevados.

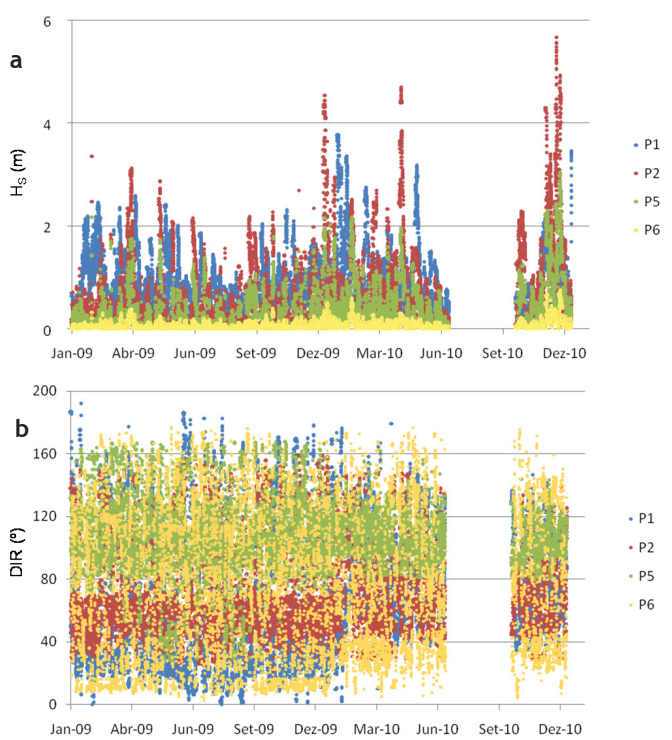

Fig. 7 - Série temporal dos valores da altura significativa $\left(H_{S}\right)$ : (a) e direcção média ( $D I R)$;

(b) para os pontos do Trajecto Norte.

\section{Resposta do navio à agitação incidente}

Como já referido anteriormente, ao longo da trajectória de entrada do navio no porto da Praia da Vitória, a faixa que pode ser ocupada pelo navio é dividida num conjunto de trechos observando-se, nos centróides de cada um desses trechos, os movimentos verticais do ponto seleccionado do navio. Aqueles centróides correspondem aos pontos P1 a P6 da fig. 5 que são os pontos onde foram determinadas as características das ondas incidentes. $\mathrm{Na}$ abordagem que aqui se descreve, estudaram-se cinco velocidades de avanço diferentes para o navio $(0 \mathrm{~m} / \mathrm{s}, 1 \mathrm{~m} / \mathrm{s}$, $2 \mathrm{~m} / \mathrm{s}, 3 \mathrm{~m} / \mathrm{s}$ e $4 \mathrm{~m} / \mathrm{s}$ ).

O navio considerado foi o "N/M Fernão Gomes", um navio com um comprimento de $114 \mathrm{~m}$, uma boca de $19 \mathrm{~m}$ e um calado de $7 \mathrm{~m}$. Começou-se por resolver no domínio da frequência, com o modelo WAMIT, os problemas de radiação e de difração do navio livre para um para um conjunto de 40 frequências igualmente distribuídas entre $0.025 \mathrm{rad} / \mathrm{s}$ e 1.0 $\mathrm{rad} / \mathrm{s}$ (períodos entre $251.3 \mathrm{~s}$ e $6.28 \mathrm{~s}$ ). A superfície molhada do casco do navio foi discretizada com 421 painéis como mostrado na fig. 8. Deste exercício resultaram os coeficientes de massa adicionada e de amortecimento do "N/M Fernão Gomes", bem como as forças exercidas pelas ondas no mesmo navio. Com estas grandezas foi possível montar e resolver as equações de movimento do navio e desses resultados obtiveram-se as funções de resposta em frequência do navio. 
RISCOS - Associação Portuguesa de Riscos, Prevenção e Segurança

QUADRo II - Parâmetros estatísticos da agitação marítima nos pontos P1 a P6.

\begin{tabular}{|c|c|c|c|c|c|c|c|}
\hline Pontos & Grandeza & Máximo & Mínimo & Média & Desvio Padrão & Gama mais $f$ & equente \\
\hline \multirow{3}{*}{ SWAN P1 } & Hs (m) & 4.58 & 0.04 & 0.85 & 0.61 & {$[0.50-1.00]$} & $(37.60 \%)$ \\
\hline & $\mathrm{Tp}(\mathrm{s})$ & 16.69 & 2.21 & 9.19 & 2.50 & [10.0 - 11.0] & (18.46\%) \\
\hline & $\operatorname{DIR}\left({ }^{\circ}\right)$ & 359.32 & 0.04 & 63.14 & 40.90 & [20.0 - 30.0] & $(16.14 \%)$ \\
\hline \multirow{3}{*}{ DREAMS P2=P2B } & Hs (m) & 5.66 & 0.00 & 0.58 & 0.75 & {$[0.00-0.50]$} & $(65.28 \%)$ \\
\hline & Tp (s) & 16.69 & 4.06 & 9.51 & 2.14 & {$[10.0-11.0]$} & (19.48\%) \\
\hline & $\operatorname{DIR}\left({ }^{\circ}\right)$ & 158.83 & 21.15 & 71.61 & 29.52 & {$[60.0-70.0]$} & (19.71\%) \\
\hline \multirow{3}{*}{ DREAMS P3 } & $\mathrm{Hs}(\mathrm{m})$ & 6.04 & 0.01 & 0.51 & 0.66 & {$[0.00-0.50]$} & $(69.87 \%)$ \\
\hline & Tp (s) & 16.69 & 4.06 & 9.51 & 2.14 & [10.0 - 11.0] & (19.48\%) \\
\hline & $\operatorname{DIR}\left({ }^{\circ}\right)$ & 138.47 & 9.18 & 53.98 & 18.23 & {$[30.0-40.0]$} & $(25.25 \%)$ \\
\hline \multirow{3}{*}{ DREAMS P4 } & $\mathrm{Hs}(\mathrm{m})$ & 1.47 & 0.00 & 0.12 & 0.15 & {$[0.00-0.50]$} & (96.87\%) \\
\hline & $\mathrm{Tp}(\mathrm{s})$ & 16.69 & 4.06 & 9.51 & 2.14 & [10.0 - 11.0] & (19.48\%) \\
\hline & $\operatorname{DIR}\left({ }^{\circ}\right)$ & 175.19 & 1.79 & 76.77 & 42.22 & {$[30.0-40.0]$} & (12.70\%) \\
\hline \multirow{3}{*}{ DREAMS P5 } & $\mathrm{Hs}(\mathrm{m})$ & 3.03 & 0.00 & 0.29 & 0.42 & {$[0.00-0.50]$} & $(80.51 \%)$ \\
\hline & $\mathrm{Tp}(\mathrm{s})$ & 16.69 & 4.06 & 9.51 & 2.14 & [10.0 - 11.0] & (19.48\%) \\
\hline & $\operatorname{DIR}\left({ }^{\circ}\right)$ & 167.76 & 28.56 & 106.14 & 19.16 & [90.0 - 100.0] & (23.88\%) \\
\hline \multirow{3}{*}{ DREAMS P6 } & $\mathrm{Hs}(\mathrm{m})$ & 0.75 & 0.00 & 0.06 & 0.08 & {$[0.00-0.50]$} & (99.48\%) \\
\hline & Tp (s) & 16.69 & 4.06 & 9.51 & 2.14 & [10.0 - 11.0] & (19.48\%) \\
\hline & $\operatorname{DIR}\left({ }^{\circ}\right)$ & 177.25 & 2.16 & 73.37 & 46.70 & {$[10.0-20.0]$} & (12.91\%) \\
\hline
\end{tabular}

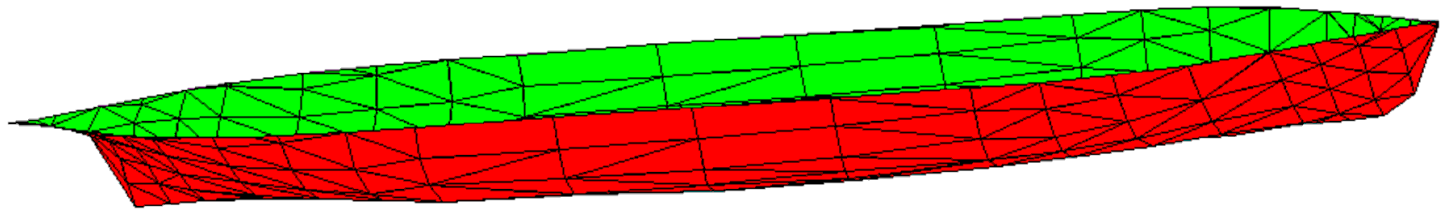

Fig. 8 - Painelização da superfície molhada do casco do navio "N/M Fernão Gomes".

Os gráficos da evolução com a relação profundidade/ calado dos coeficientes de massa adicionada e de amortecimento, fig. 9, para o modo de oscilação de arfagem ("heave"), mostram que estes coeficientes são muito sensíveis à profundidade da zona onde o navio está, aumentando o valor daqueles coeficientes com a redução da profundidade.

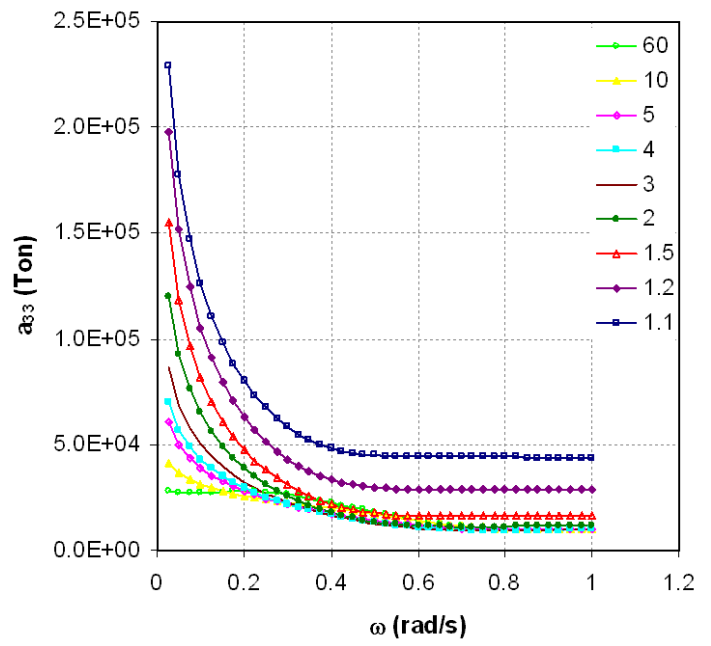

No gráfico do coeficiente de amortecimento verificase que para os períodos mais baixos uma relação profundidade/calado igual a 4 já produz valores semelhantes aos de valores maiores da mesma relação, algo que está de acordo com o esperado, atendendo a que estes coeficientes estão relacionados com a geração de ondas em águas de outra forma paradas.

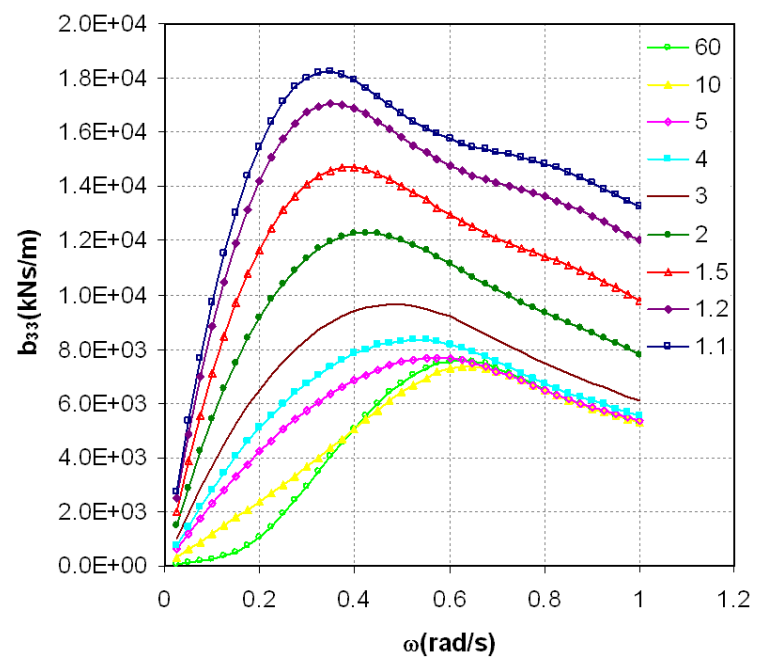

Fig. 9 - Influência da relação profundidade/calado nos coeficientes de massa adicionada e de amortecimento para o modo de arfagem do "N/M Fernão Gomes". 
No que diz respeito à força de difracção segundo a arfagem, a fig. 10, com a influência da profundidade nesta força quando o "N/M Fernão Gomes" está sujeito a ondas que fazem um ângulo de $30^{\circ} \mathrm{com}$ o eixo longitudinal do navio, mostra que, para valores da relação profundidade/calado superiores a 3 , já é difícil distinguir a influência desta relação naquela força. Além disso, a figura mostra que há um aumento daquela força quando a profundidade diminui, para períodos pequenos, e uma diminuição para períodos grandes. Outro resultado interessante nesse gráfico é a convergência dos valores da força, independentemente da profundidade, para o valor correspondente à impulsão hidrostática à medida que o período da onda incidente aumenta.

Para um ângulo de incidência de $30^{\circ}$, a fig. 11 ilustra a influência da relação profundidade/calado na amplitude do movimento vertical de um ponto no "N/M Fernão Gomes" cujas coordenadas no referencial do navio são $(45.5,5.4,0.0)$. A figura mostra que a diminuição da profundidade implica um aumento do período onde ocorre o máximo da resposta, verificando-se também um ligeiro aumento do valor desta amplitude máxima.

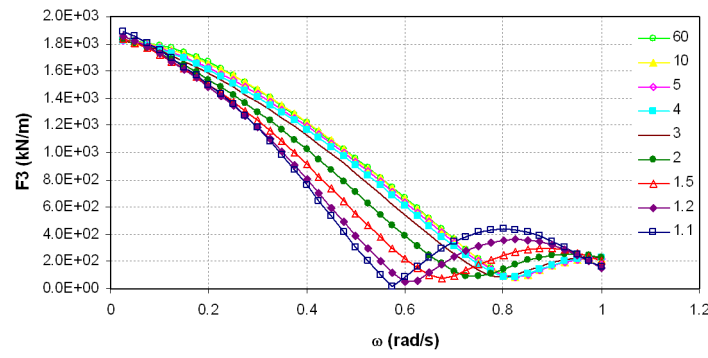

Fig. 10 - Influência da relação profundidade/calado na força vertical no "N/M Fernão Gomes" provocada por ondas incidentes cujo vector número de onda faz um ângulo de $30^{\circ} \mathrm{com}$ o eixo longitudinal do navio.

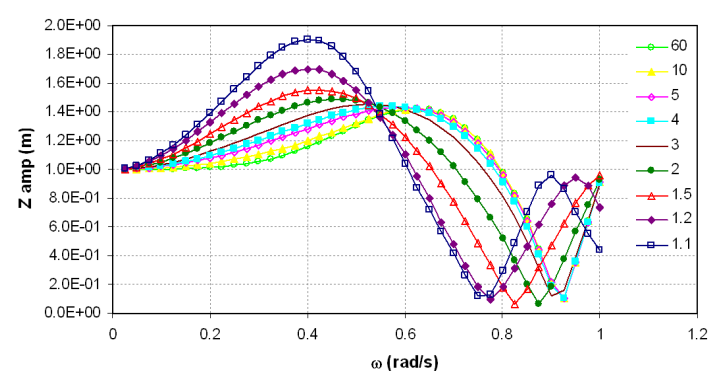

Fig. 11 - Influência na amplitude do movimento vertical do ponto $(45.5,5.4,0.0)$ do "N/M Fernão Gomes" da relação profundidade/calado da zona onde o navio está para um ângulo de $30^{\circ}$ entre o eixo longitudinal do navio e o vector número de onda da onda incidente no navio.

Importa referir que os valores apresentados nos gráficos são os correspondentes a uma onda incidente com $1 \mathrm{~m}$ de amplitude o que, para algumas situações, pode ser muito mais do que o expectável no local onde está o navio.

Os movimentos, cujas amplitudes o modelo numérico WAMIT calcula, são os da origem do referencial baricêntrico do navio, mostrado na fig. 1. Como tal, para se obter a amplitude do movimento vertical de qualquer ponto do navio, é necessário avaliar a componente vertical do produto externo do vector velocidade de rotação pelo vector de posição desse ponto do navio em relação à origem do referencial baricêntrico. Importa referir que as componentes do vector velocidade de rotação são grandezas complexas pois, para além do módulo da velocidade de rotação em torno de cada um dos eixos, importa conhecer também a fase da mesma velocidade.

No fim deste procedimento, resulta uma matriz de transferência que estima a amplitude da componente vertical do movimento de um ponto do navio a partir da profundidade da zona onde o navio se desloca, do período da onda e do ângulo entre o eixo longitudinal do navio e o vector número de onda da onda incidente no navio.

No QUADRo III apresenta-se um resumo dos resultados, em termos de alturas significativas, $H_{S}$, dos movimentos verticais do navio sujeito a cada um dos 14573 estados de agitação com 3 horas de duração que foram estimados para o período entre 1 de janeiro de 2009 e 31 de dezembro de 2010, para os pontos de cada um dos dois trajetos em análise, enquanto no QUADRo IV se apresenta a distribuição das alturas dos movimentos verticais do navio observados para a totalidade dos mesmos 14573 estados de agitação.

Como se pode constatar naqueles dois quadros existe uma tendência clara para o aumento das alturas dos movimentos verticais do navio à medida que aumenta a velocidade de avanço do navio, qualquer que seja o trajeto considerado.

Começando pelo Trajeto Sul, no Quadro III observa-se um crescimento, com a velocidade de avanço, do valor médio das alturas significativas do movimento vertical, enquanto no QUADRo IV, à medida que aquela velocidade cresce, aumenta também a percentagem de alturas de movimentos verticais do navio na gama mais alta ali considerada $[0.15 \mathrm{~m}, 0.20 \mathrm{~m}$ ] (à excepção do ponto $\mathrm{P} 2$ ). Ainda no que se refere às alturas significativas do movimento vertical do navio, pode afirmar se, a partir do QUADRo III, que o desvio padrão da amostra obtida aumenta com a velocidade do navio, o que sugere uma maior variabilidade dos movimentos verticais do navio.

Tal como já se verificara para as características da agitação marítima, QUADRo II, no mesmo Trajeto Sul, o valor médio das alturas significativas dos movimentos verticais do navio associados a cada estado de agitação diminui à medida que o navio se desloca para o interior da bacia abrigada. Contudo, este padrão não é observado no valor máximo das mesmas alturas significativas, ocorrendo até valores muito superiores aos observados nas alturas significativas dos estados de agitação incidentes apresentados no QUADRO II. 
RISCOS - Associação Portuguesa de Riscos, Prevenção e Segurança

QUADRo III - Valores das alturas significativas dos movimentos verticais do navio nos pontos dos dois trajetos.

\begin{tabular}{|c|c|c|c|c|c|c|}
\hline \multicolumn{2}{|c|}{ Pontos } & Velocidades $(\mathrm{m} / \mathrm{s})$ & Máximo $(\mathrm{m})$ & Mínimo $(\mathrm{m})$ & Média (m) & Desvio Padrão (m) \\
\hline & \multirow{5}{*}{ P1 } & 0 & 5.005 & 0.001 & 0.950 & 0.716 \\
\hline & & 1 & 5.306 & 0.002 & 0.979 & 0.734 \\
\hline & & 2 & 5.596 & 0.004 & 1.030 & 0.759 \\
\hline & & 3 & 5.865 & 0.005 & 1.091 & 0.784 \\
\hline & & 4 & 6.034 & 0.006 & 1.147 & 0.820 \\
\hline \multirow{15}{*}{ 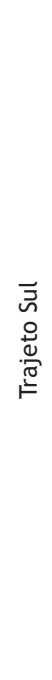 } & \multirow{5}{*}{ P2 } & 0 & 5.817 & 0.003 & 0.530 & 0.700 \\
\hline & & 1 & 6.429 & 0.003 & 0.579 & 0.769 \\
\hline & & 2 & 6.973 & 0.004 & 0.642 & 0.843 \\
\hline & & 3 & 7.398 & 0.005 & 0.703 & 0.918 \\
\hline & & 4 & 7.749 & 0.005 & 0.768 & 1.001 \\
\hline & \multirow{5}{*}{ P3 } & 0 & 6.602 & 0.003 & 0.439 & 0.619 \\
\hline & & 1 & 7.115 & 0.003 & 0.496 & 0.682 \\
\hline & & 2 & 7.519 & 0.004 & 0.555 & 0.743 \\
\hline & & 3 & 7.815 & 0.007 & 0.611 & 0.804 \\
\hline & & 4 & 7.918 & 0.009 & 0.662 & 0.861 \\
\hline & \multirow{5}{*}{ P4 } & 0 & 1.757 & 0.001 & 0.099 & 0.135 \\
\hline & & 1 & 1.952 & 0.000 & 0.105 & 0.143 \\
\hline & & 2 & 2.216 & 0.000 & 0.115 & 0.160 \\
\hline & & 3 & 2.555 & 0.000 & 0.128 & 0.185 \\
\hline & & 4 & 2.733 & 0.000 & 0.145 & 0.220 \\
\hline \multirow{15}{*}{ 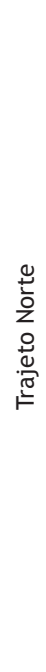 } & \multirow{5}{*}{ P2B } & 0 & 6.460 & 0.003 & 0.564 & 0.744 \\
\hline & & 1 & 6.877 & 0.002 & 0.607 & 0.801 \\
\hline & & 2 & 7.290 & 0.004 & 0.666 & 0.872 \\
\hline & & 3 & 7.609 & 0.005 & 0.724 & 0.940 \\
\hline & & 4 & 7.925 & 0.005 & 0.788 & 1.020 \\
\hline & \multirow{5}{*}{ P5 } & 0 & 3.347 & 0.001 & 0.268 & 0.428 \\
\hline & & 1 & 3.691 & 0.001 & 0.299 & 0.469 \\
\hline & & 2 & 4.002 & 0.002 & 0.334 & 0.515 \\
\hline & & 3 & 4.240 & 0.002 & 0.367 & 0.557 \\
\hline & & 4 & 4.408 & 0.002 & 0.399 & 0.598 \\
\hline & \multirow{5}{*}{ P6 } & 0 & 0.832 & 0.000 & 0.065 & 0.099 \\
\hline & & 1 & 0.830 & 0.000 & 0.064 & 0.098 \\
\hline & & 2 & 0.881 & 0.000 & 0.064 & 0.098 \\
\hline & & 3 & 0.919 & 0.000 & 0.063 & 0.098 \\
\hline & & 4 & 0.945 & 0.000 & 0.063 & 0.098 \\
\hline
\end{tabular}

Da análise dos resultados obtidos para o Trajecto Norte pode concluir-se que é seguida a tendência já evidenciada pelos valores relativos ao Trajecto Sul. Apenas para o ponto $\mathrm{P} 6$, onde a média das alturas significativas dos movimentos verticais do navio já é muito baixa, não é clara tal evolução.

\section{Avaliação da probabilidade de ocorrência}

Para ilustrar e testar a metodologia de avaliação da probabilidade de ocorrência apresentada anteriormente, definiu-se, a título de exemplo, um limiar de $0.5 \mathrm{~m}$ para a altura do movimento vertical do navio considerado e avaliou-se a probabilidade de ocorrência de alturas superiores àquele limiar nos pontos dos dois percursos e para diferentes velocidades de avanço.

Embora o número total de ondas nos estados de agitação ocorridos nos dois anos em análise já tenha sido utilizado para determinar as distribuições de alturas dos movimentos verticais do navio do QUADRo IV, apenas na coluna "Total de observações" do Quadro V e do Quadro VI fica evidente que, aparte o ponto $\mathrm{P} 1$, esse número é o mesmo em todos os pontos dos trajetos Sul e Norte. Tal deve-se ao facto de o modelo numérico utilizado para a propagação das ondas para o interior da bacia portuária não considerar variações no período da onda. A diferença entre o ponto $\mathrm{P} 1$ e os restantes pontos é consequência de 
QUADRo IV - Distribuição das alturas dos movimentos verticais do navio nos pontos dos dois trajetos.

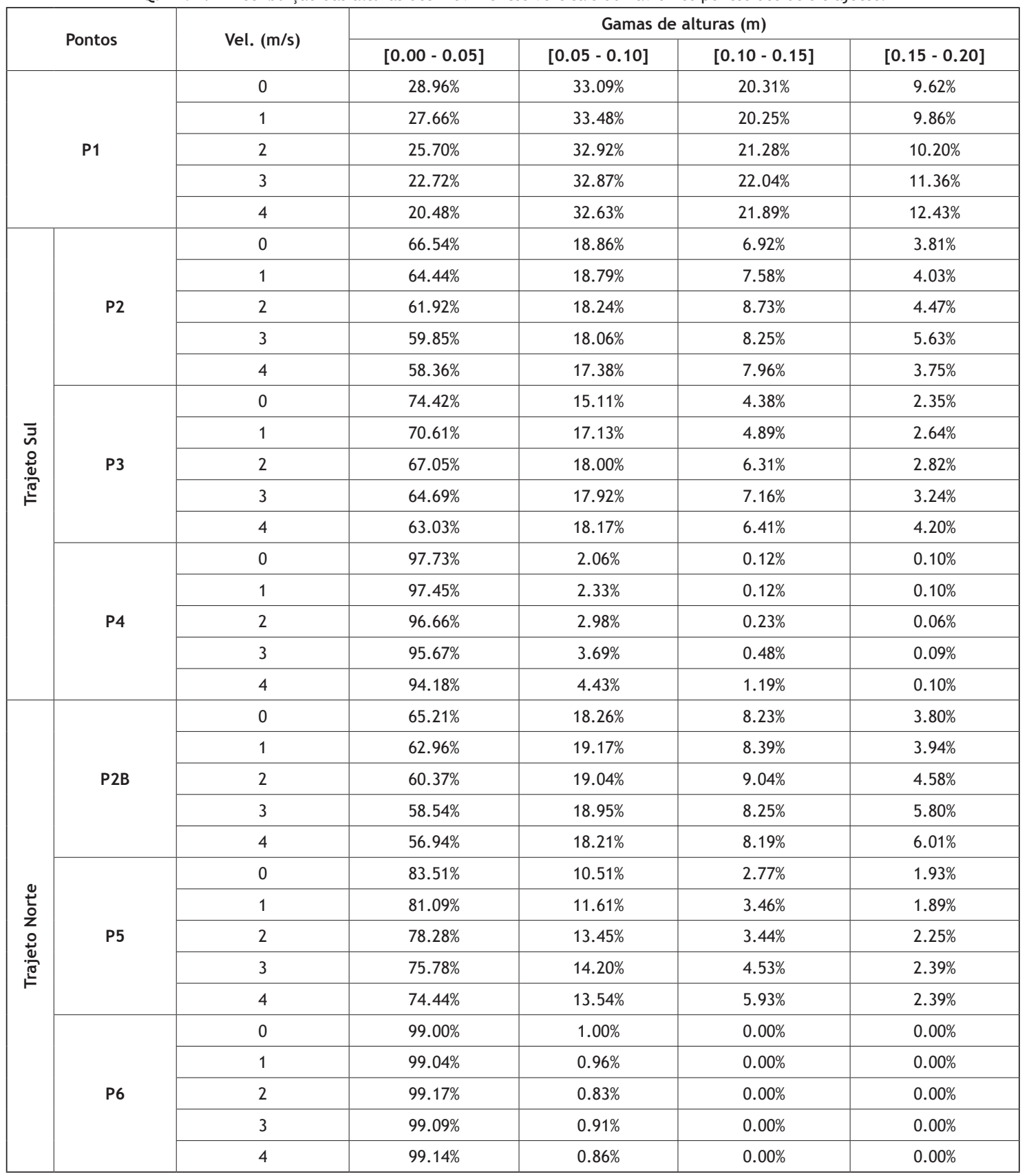

QUADRo V - Influência da velocidade de avanço no número de observações de alturas dos movimentos verticais do navio que ultrapassam o limiar de $0.5 \mathrm{~m}$ em cada ponto dos dois trajetos.

\begin{tabular}{|c|c|c|c|c|c|c|c|}
\hline \multirow{2}{*}{\multicolumn{2}{|c|}{ Ponto do trajeto }} & \multirow{3}{*}{$\begin{array}{c}\text { Total de observações } \\
3981043\end{array}$} & \multicolumn{5}{|c|}{ Velocidade de avanço do navio (ms-1) } \\
\hline & & & \multirow{2}{*}{$\begin{array}{c}0.0 \\
937629\end{array}$} & \multirow{2}{*}{$\begin{array}{c}1.0 \\
974745\end{array}$} & \multirow{2}{*}{$\begin{array}{c}2.0 \\
1060848\end{array}$} & \multirow{2}{*}{$\begin{array}{c}3.0 \\
1180112\end{array}$} & \multirow{2}{*}{$\begin{array}{c}4.0 \\
1310250\end{array}$} \\
\hline & P1 & & & & & & \\
\hline \multirow{3}{*}{ 菾亏 } & P2 & 3442849 & 433175 & 493116 & 584020 & 672049 & 763888 \\
\hline & P3 & 3442849 & 295814 & 364136 & 442072 & 521187 & 595255 \\
\hline & P4 & 3442849 & 10019 & 12244 & 17722 & 28875 & 47681 \\
\hline \multirow{3}{*}{ 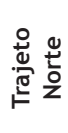 } & P2A & 3442849 & 468749 & 518670 & 606154 & 692755 & 787054 \\
\hline & P5 & 3442849 & 173787 & 208699 & 255220 & 308339 & 367291 \\
\hline & P6 & 3442849 & 2644 & 2558 & 2641 & 2736 & 2789 \\
\hline
\end{tabular}


o procedimento de transferência das características da agitação marítima do exterior (ponto P1) para o interior da bacia portuária (restantes pontos) não ter propagado alguns dos estados de agitação previstos para o ponto P1.

Os resultados destes quadros estão de acordo com os dos quadros anteriores que mostram um crescimento da altura dos movimentos verticais do navio com a velocidade de avanço do mesmo e que agora se traduz no aumento do número de ocorrências de ultrapassagem do limiar de $0.5 \mathrm{~m}$.

\section{Conclusão}

Apresentou-se neste artigo uma metodologia para avaliar a probabilidade de ocorrência de um acontecimento perigoso que consiste em a altura dos movimentos verticais de um ponto selecionado de um navio ultrapassar um limiar pré-definido. Tal metodologia baseia-se na determinação das características da agitação marítima em pontos notáveis do trajeto seguido pelo navio na sua manobra e na avaliação da resposta do navio a ondas monocromáticas.

Este procedimento é uma contribuição interessante para avaliação do risco associado a este tipo de fenómeno pois permite o cálculo de um dos factores presentes na fórmula usual para a determinação do risco. De realçar aqui a abordagem para a avaliação do número esperado de ondas do estado de agitação que ultrapassa o limiar pré estabelecido e que se baseia na utilização da distribuição de Rayleigh para descrever a distribuição das alturas dos movimentos verticais do ponto seleccionado do navio.

A aplicação do procedimento ao caso de teste do porto da Praia da Vitória, Açores, não só confirmou o bom desempenho deste procedimento, servindo também para se inferir da influência da velocidade de avanço do navio na altura dos movimentos verticais de um ponto no "N/M Fernão Gomes", o navio para o qual se determinaram as distribuições daquelas alturas ao longo de dois trajetos no interior daquele porto. Os resultados obtidos para os dois anos de previsões de agitação marítima disponíveis mostraram que o aumento da velocidade de avanço do navio (desde $0 \mathrm{~m} / \mathrm{s}$ até $4 \mathrm{~m} / \mathrm{s}$ ) implica o aumento da altura dos movimentos.

A resposta do navio foi obtida considerando que a agitação marítima no interior da bacia portuária pode ser descrita por um espectro JONSWAP. Como esta não é a forma do espectro mais adequada para águas pouco profundas, como são as esperadas em bacias portuárias, o próximo teste a realizar neste procedimento incluirá outros espectros para a agitação no interior da bacia portuária, analisando-se a influência da forma do espectro nos valores obtidos para a probabilidade de ocorrência do acontecimento perigoso.

\section{Agradecimentos}

Os autores agradecem à Fundação para a Ciência e a Tecnologia (FCT) o financiamento concedido através dos projectos Hidralerta e EROS.

\section{Referências bibliográficas}

Bools, N.; RIs, R.C.; Holthuissen, L.H. (1999) - "A thirdgeneration wave model for coastal regions, Part I, Model description and validation." J. Geophysical Research, 104, C4, pp. 7649-7666.

Faltinsen, O.M. (1990) - Sea loads on ships and offshore structures. Cambridge University Press, 340 p.

FoRTES, C.J.E.M. (2002). Transformações não lineares de ondas em zonas portuárias. Análise pelo método dos elementos finitos. Tese de doutoramento. Engenharia Mecânica, IST.

GodA, Y. (1985). "Random Seas and Design of Maritime Structures". Advanced series on ocean engineering, v.15. World Scientific Publishing, Singapore.

Hasselmann, K.; Barnett, T.P.; Bouws, E.; Carlson, H.; Cartwright, D.E.; Enke, K.; Ewing, J.A.; Gienapp, H.; Hasselmann, D.E.; Kruseman, P.; Meerburg, A.;

QUADRO VI - Influência da velocidade de avanço na probabilidade de ocorrência de alturas dos movimentos verticais do navio que ultrapassam o limiar de $0.5 \mathrm{~m}$ em cada ponto dos dois trajetos.

\begin{tabular}{|c|c|c|c|c|c|c|c|}
\hline \multirow{2}{*}{\multicolumn{2}{|c|}{ Ponto do trajeto }} & \multirow{3}{*}{$\begin{array}{c}\text { Total de observações } \\
3981043\end{array}$} & \multicolumn{5}{|c|}{ Velocidade de avanço do navio $\left(\mathrm{ms}^{-1}\right)$} \\
\hline & & & \multirow{2}{*}{$\begin{array}{c}0.0 \\
0.2355\end{array}$} & \multirow{2}{*}{$\begin{array}{c}1.0 \\
0.2448\end{array}$} & \multirow{2}{*}{$\begin{array}{c}2.0 \\
0.2665\end{array}$} & \multirow{2}{*}{$\begin{array}{c}3.0 \\
0.2964\end{array}$} & \multirow{2}{*}{$\begin{array}{c}4.0 \\
0.3291\end{array}$} \\
\hline & P1 & & & & & & \\
\hline \multirow{3}{*}{ 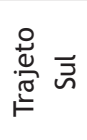 } & P2 & 3442849 & 0.1258 & 0.1432 & 0.1696 & 0.1952 & 0.2219 \\
\hline & P3 & 3442849 & 0.0859 & 0.1058 & 0.1284 & 0.1514 & 0.1729 \\
\hline & P4 & 3442849 & 0.0029 & 0.0036 & 0.0051 & 0.0084 & 0.0138 \\
\hline \multirow{3}{*}{ 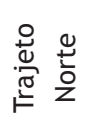 } & $\mathrm{P} 2 \mathrm{~A}$ & 3442849 & 0.1362 & 0.1507 & 0.1761 & 0.2012 & 0.2286 \\
\hline & P5 & 3442849 & 0.0505 & 0.0606 & 0.0741 & 0.0896 & 0.1067 \\
\hline & P6 & 3442849 & 0.0008 & 0.0007 & 0.0008 & 0.0008 & 0.0008 \\
\hline
\end{tabular}


Muller, P.; Olbers, D.J.; Richter, K.; Sell, W.; WALDEN, H. (1973) - "Measurements of wind-wave growth and swell decay during the Joint North Sea Wave Project (JONSWAP)." Ergnzungsheft zur Deutschen Hydrographischen Zeitschrift Reihe, $\mathrm{A}(8)$ (Nr. 12), p.95.

Neves, D.R.C.B.; Zózimo, A.C.; Pinheiro, L.V.; Fortes, C.J.E.M. (2009) - “GUIOMAR: Geo(graphical) User Interface for cOastal and MARine Modeling. Supported Decision System." Journal of Coastal Research, SI 56 (Proc. 10th International Coastal Symposium), pp.1542-1546.

Neves, D.R.; Santos, J.A.; Reis, M.T.; Fortes, C.J.; Simões, A.; Azevedo, E.B.; Rodrigues, M.C. (2012) "Metodologia de avaliação do risco associado ao galgamento de estruturas marítimas. Aplicação ao porto e à baía da Praia da Vitória, Açores, Portugal." Revista de Gestão Costeira Integrada, 12(3), pp. 291-312.

Newman, J.N.; Sclavounos, P.D. (1988) - The computation of wave loads on large offshore structures. Proc. Boss 88, Norway, pp. 1-19.

Rodrigues, S.; SAntos, J.A.; Lemos, R. (2011A) - “Interacção da agitação marítima com navios em manobra na entrada de portos". Congresso de Métodos Numéricos em Engenharia 2011, Coimbra, 14 a 17 de Junho de 2011.
Rodrigues, S.; Santos, J.A.; Neves, D.R.; Oliveira, R. (2011B) - "Movimentos de navios na entrada de um porto induzidos pela agitação marítima”. 7as Jornadas Portuguesas de Engenharia Costeira e Portuária, Porto, 6 e 7 de Outubro de 2011.

Silva, E.; Santos, J.A.; ReIs, M.T. (2011) - "Porto da Praia da Vitória. Estimativa dos galgamentos da protecção marginal da baía". 7as Jornadas Portuguesas de Engenharia Costeira e Portuária, Porto, 6 e 7 de Outubro de 2011.

Simões, A.; Tomé, R.; ReIs, F.; Azevedo, E. (2009) - “Avaliação da Qualidade das Previsões de Agitação Marítima no Arquipélago dos Açores”. Projectos CLIMAAT e CLIMAAT II, INTERREG IIIB - Açores, Madeira e Canárias, MAC/2.3/A3 - 03/MAC/2.3/A5.

Tolman, H.L. (1999) - User manual and system documentation of WAVEWATCH-III version 1.18. NOAA / NWS / NCEP / OMB technical note 166, $110 \mathrm{pp}$.

Tomé, R.; Ramalho, C.; Ferreira, J.P.; Miranda, P.M.A. (2005) "Previsão do tempo nos Açores com Modelos de Alta Resolução”. 4 Simpósio de Meteorologia e Geofísica da APMG, Sesimbra, Portugal.

Zózimo, A.C.; Fortes, C.J.E.M. (2007) - Estado actual e desenvolvimentos futuros do sistema integrado de apoio à tomada de decisão em engenharia costeira: GUIOMAR - Tecnologias da Água, 52 (Edição IV):54-65, Lisboa, Portugal. 